\title{
Low seroprevalence and low incidence of infection with Toxoplasma gondii (Nicolle et Manceaux, 1908) in pediatric hematopoietic cell transplantation donors and recipients: Polish nationwide study
}

\author{
Krzysztof Czyzewski ${ }^{1}$, Jowita Fraczkiewicz ${ }^{2}$, Malgorzata Salamonowicz ${ }^{2}$, Anna Pieczonka ${ }^{3}$, \\ Olga Zajac-Spychala ${ }^{3}$, Agnieszka Zaucha-Prazmo ${ }^{4}$, Jolanta Gozdzik ${ }^{5}$ and Jan Styczynski ${ }^{1}$
}

\begin{abstract}
${ }^{1}$ Department of Pediatric Hematology and Oncology, Collegium Medicum in Bydgoszcz, Nicolaus Copernicus University in Torun, Bydgoszcz, Poland;

${ }^{2}$ Department of Pediatric Transplantation, Oncology and Hematology, Medical University, Wroclaw, Poland; ${ }^{3}$ Department of Pediatric Oncology, Hematology and Transplantology, University of Medical Sciences, Poznan, Poland; ${ }^{4}$ Department of Pediatric Hematology, Oncology and Stem Cell Transplantation, Medical University, Lublin, Poland;

${ }^{5}$ Stem Cell Transplant Center, University Children's Hospital, Department of Clinical Immunology and Transplantology, Jagiellonian University Collegium Medicum, Krakow, Poland.
\end{abstract}

\begin{abstract}
Toxoplasmosis is a potentially fatal complication after hematopoietic cell transplantation (HCT). Pre-transplant seropositivity of graft recipient to Toxoplasma gondii (Nicolle et Manceaux, 1908) is an important factor for disease reactivation after HCT. As toxoplasmosis epidemiology varies all over the world, we performed a Polish nationwide retrospective cohort study to determine the seroprevalence of toxoplasmosis in donors and pediatric allogeneic and autologous HCT recipients and the incidence of clinically evident toxoplasmosis in this patient group. Polish adult donors had higher anti- $T$. gondii seroprevalence than Polish pediatric donors $(28 \%$ vs $8 \% ; \mathrm{OR}=4.4 ; \mathrm{p}=0.02)$ and allo-HCT recipients $(28 \%$ vs $17 \% ; \mathrm{OR}=1.9 ; \mathrm{p}=0.01)$. Clinically apparent disease occurred in $1 \%$ of allo-HCT recipients: it was diagnosed by PCR as cerebral and/or ocular toxoplasmosis and successfully treated with antiprotozoal therapy. Regarding current practice, no prospective screening for infection of $T$. gondii in pediatric HCT centres is being performed, but, vast majority of HCT pediatric patients are receiving anti- $T$. gondii active prophylaxis. Since pre-HCT $T$. gondii serology was not assessed in all HCT; recipients, we propose this test should be a standard practice. Standardisation of management with infection of T. gondii in children after HCT is needed.
\end{abstract}

Keywords: bone marrow transplantation, children, prophylaxis, toxoplasmosis, treatment, trimethoprime, sulfamethoxazole

Toxoplasma gondii (Nicolle et Manceaux, 1908) is an intracellular parasite that causes infection in most mammals worldwide (Olariu et al. 2015). The infection is transmitted to humans by ingestion of food or water contaminated with oocysts shed by cats or by eating raw or undercooked meat containing tissue cysts (Martino et al. 2000, Olariu et al. 2015, Dard et al. 2018). Seroprevalence $T$. gondii of varies widely between countries (10-95\%) (Olariu et al. 2015, Gatti-Mays et al. 2016, Isa et al. 2016, Berrett et al. 2018).

Although $T$. gondii causes asymptomatic infection in immunocompetent hosts and most newborns, it can severely affect congenitally infected infants and immunocompromised patients (Martino et al. 2000, Olariu et al. 2015). Toxoplasmosis was formerly considered a rare disease among hematopoietic cell transplantation (HCT) recipients with reported incidences varying from 0.8 to $8 \%$, depending on the seroprevalence of $T$. gondii in the studied population (Decembrino et al. 2017, Prestes et al. 2018). Recent data highlighted post-HCT toxoplasmosis as a potential life-threatening disease with a poor prognosis and reported mortality rates of $60-90 \%$ if the onset is early after transplantation (Decembrino et al. 2017, Prestes et al. 2018). An acute, fulminating, disseminated infection or single-organ disease (usually encephalitis) is usually seen in highly immunocompromised individuals, in whom these infections appear to result from reactivation of latent tissue parasites in seropositive individuals (Martino et al. 2000). The most frequently involved organs are the brain, lungs and heart (Hakko et al. 2013).

Address for correspondence: Krzysztof Czyzewski, Department of Pediatric Hematology and Oncology, Collegium Medicum in Bydgoszcz, Nicolaus Copernicus University in Torun, ul. Sklodowskiej-Curie 9, 85-094 Bydgoszcz, Poland. Phone: +48 5258548 60; Fax: +48 52-585 4087; Email: k.czyzewski@cm.umk.pl 
Table 1. Definitions for toxoplasmosis after hematopoietic cell transplantation - modified from Martino et al. (2000)

\begin{tabular}{|c|c|c|}
\hline \multicolumn{2}{|c|}{ Toxoplasmosis classification } & \multirow{2}{*}{$\begin{array}{l}\text { Definition } \\
\text { Histological or cytological demonstration of tachyzoites in tissue samples obtained either by biopsy, BAL } \\
\text { or at autopsy. Isolation of the parasite by culture in these samples would be evidence of the disease. }\end{array}$} \\
\hline \multirow{3}{*}{$\begin{array}{l}\text { Toxoplasmosis } \\
\text { disease }\end{array}$} & Definite toxoplasmosis & \\
\hline & $\begin{array}{l}\text { Probable toxoplasmosis } \\
\text { (PCR-documented) }\end{array}$ & $\begin{array}{l}\text { Clinical and radiological evidence suggestive of organ involvement plus at least one positive PCR test } \\
\text { from blood, CSF and/or BAL, but no histologic confirmation and absence of another pathogen which may } \\
\text { explain the findings. }\end{array}$ \\
\hline & $\begin{array}{l}\text { Possible toxoplasmosis } \\
\text { (Imaging-documented) }\end{array}$ & $\begin{array}{l}\text { CT or MRI highly suggestive of CNS toxoplasmosis (as considered by each hospital's neuroradiologists) and } \\
\text { response to anti-Toxoplasma therapy, but no laboratory evidence of toxoplasmosis and absence of another } \\
\text { pathogen which may explain the findings. }\end{array}$ \\
\hline $\begin{array}{l}\text { Toxoplasmosis } \\
\text { infection }\end{array}$ & & $\begin{array}{l}\text { Positive PCR in blood in a patient without any evidence of organ involvement or seroconversion for Toxo- } \\
\text { plasma gondii after transplant in a previously sero-negative patient (with or without fever). }\end{array}$ \\
\hline
\end{tabular}

There are conflicting data on primary prophylaxis against T. gondii after HCT (Gajurel et al. 2015, Ullmann et al. 2016). Moreover, myelosuppressive effect of trimethoprim/sulfamethoxazole (TMP/SMX), a commonly used prophylactic agent in varying dosing, can be problematic in this population (Gajurel et al. 2015). This has created a great deal of discrepancy regarding appropriate prophylaxis against $T$. gondii in the setting of HCT (Gajurel et al. 2015).

As epidemiology of toxoplasmosis varies all over the world, we performed a Polish nationwide retrospective cohort study to determine the seroprevalence of toxoplasmosis in donors and pediatric allogeneic HCT (allo-HCT) and autologous HCT (auto-HCT) recipients and the incidence of clinically evident toxoplasmosis in this patient group. We also analysed the clinical course of toxoplasmosis disease in pediatric HCT recipients. Additionally, we determined the current practices in prophylaxis, diagnostics and treatment of toxoplasmosis in all pediatric HCT centres in Poland.

\section{MATERIALS AND METHODS}

Design of the study. In this retrospective, multicentre, nationwide cohort study all Polish pediatric HCT centres (Bydgoszcz, Krakow, Lublin, Poznan, Wroclaw) participated over a period of two years (2015-2016). The information on all recipients and donors was collected in the centres and analysed centrally by two independent researchers. Apart from basic data on donors, recipients, and type of transplants, the data also included information on the Toxoplasma gondii immunological serostatus (anti-T. gon$d i i$-IgG) in of donors and recipients, screening for $T$. gondii infection/reactivation and anti-T. gondii prophylaxis. The centres also reported cases of clinically overt toxoplasmosis. The diagnostics of toxoplasmosis in suspected cases included magnetic resonance imaging (MRI) and commercially available real-time PCR, which was performed on peripheral blood, cerebrospinal or vitreous fluid. This study was approved by the Ethics Committee of Collegium Medicum in Bydgoszcz, Nicolaus Copernicus University in Torun.

Anti-infective prophylaxis. Uniform, standard prophylaxis was applied for all patients undergoing HCT (Ljungman et al. 2008, Styczynski and Gil 2008, Styczynski et al. 2009) in the peri-transplantation period and in the post-HCT period. TMP $6 \mathrm{mg} / \mathrm{kg} /$ day + SMX $30 \mathrm{mg} / \mathrm{kg} /$ day three times a week was used as Pneumocystis jiroveci Frenkel, 1976 pneumonia $(P j P)$ prophylaxis active against
T. gondii or aerolised pentamidine was used for anti-PjP prophylaxis with no additional prophylaxis against $T$. gondii.

Definitions. Infection of $T$. gondii and toxoplasmosis disease were defined according to European Group for Blood and Marrow Transplantation Infectious Diseases Working Party guidelines (Martino et al. 2000) (Table 1).

Statistical analysis. The chi-square test with odds ratio (OR) and confidence intervals $(95 \% \mathrm{CI})$ were used to calculate the difference in occurrences of categorical variables between groups. All reported $\mathrm{p}$-values are two-sided; $\mathrm{p}<0.05$ was considered as statistically significant.

\section{RESULTS}

Demographics. A total of 664 individuals were included in the study: 287 allo-HCT recipients (including 7 from Ukraine), 90 auto-HCT pediatric recipients, and 287 donors of hematopoietic stem cells. Allo-HCT recipients included 181 males and 106 females at median age of eight years (range, 0.1-26), while auto-HCT recipients included 48 males and 42 females with median age of 4.7 years (range, 0.6-21). Among 287 donors, Poland was country of origin in $212(74 \%)$ cases (including 49 siblings $<18$ years), Germany in $56(20 \%)$, other countries (USA $(n=6)$, Israel $(n=4)$, Italy $(n=3)$, Spain $(n=2)$, Australia $(n=1)$, France $(n=1)$, Sweden $(n=1)$, Taiwan $(n=1)$ for $19(6.6 \%)$ transplants. Of 212 Polish donors 124 were male and 88 female with median age of 25 years (range, 1-49).

Seroprevalence of toxoplasmosis of in adult and pediatric donors and pediatric recipients. Among allo-HCT recipients, pre-transplant Toxoplasma gondii serology was available for $87 \%(250 / 287)$ patients: $19 \%$ (47/250) were IgG-positive and $81 \%(203 / 250)$ naive for the infection (Table 2). In auto-HCT recipients, T. go ndii serology was available for $47 \%$ (42/90) patients, including 14\% (6/42) IgG-positive before transplantation and $86 \%$ (36/42) IgG-negative. T. gondii serostatus was available in $78 \%$ (166/212) Polish donors: 24\% (39/166) were IgG-positive and $77 \%(127 / 166)$ were IgG-negative.

In comparison to donors from Poland and Germany, we found a high rate $(58 \%)$ of untested donors from other countries. In comparison to allo-HCT recipients we found also high number of untested auto-HCT recipients $(13 \%$ vs 53\%). However, among those who were tested, no difference was found in seropositivity between allo- and auto-HCT recipients found ( $19 \%$ vs $14 \% ; \mathrm{p}>0.05)$. 
Table 2. Characteristics of donors and recipients and T. gondii seroprevalence

\begin{tabular}{|c|c|c|c|c|c|}
\hline & \multicolumn{3}{|c|}{ Donors (country of origin) } & \multicolumn{2}{|c|}{ Recipients } \\
\hline & Poland & Germany & Other* & Allo & Auto \\
\hline Number of individuals & 212 & 56 & 19 & 287 & 90 \\
\hline Age (median, range) & $25(1-49) \mathrm{yrs}$ & $31(18-58)$ yrs & $27.5(18-44) \mathrm{yrs}$ & 8 yrs (1 mo-26 yrs) & $4.7 \mathrm{yrs}(7 \mathrm{mo}-21 \mathrm{yrs})$ \\
\hline Sex (male/female) & $124 / 88$ & $37 / 19$ & $8 / 11$ & $181 / 106$ & $48 / 42$ \\
\hline Anti-Toxo-IgG $(+)$ & $39(23 \%)$ & $10(22 \%)$ & $1(13 \%)$ & $47(19 \%)$ & $6(14 \%)$ \\
\hline Anti-Toxo-IgG (-) & $127(77 \%)$ & $35(78 \%)$ & $7(88 \%)$ & $203(81 \%)$ & $36(86 \%)$ \\
\hline not tested & 46 & 11 & 11 & 37 & 48 \\
\hline
\end{tabular}

There was no significant difference between Polish donors and allo-recipients in anti- $T$. gondii-IgG seropositivity $(23 \%$ vs $19 \%$; $>0.05)$. When patients from Ukraine (seven IgG+; two IgG-) were excluded from the analysis, the sub-group of Polish allo-HCT recipients included 17\% (40/241) IgG+ and 83\% (201/241) IgG- patients (37 of Polish allo-HCT recipients were untested). Donors from Poland included 23\% (49/212 donors) pediatric and 77\% (163/212) adults. In the Polish pediatric donors group T. gondii serology was available for $76 \%$ (37/49) donors. Anti-T. gondii-IgG antibodies were present just in $8.1 \%$ (3/37), whereas $92 \%$ (34/37) donors were seronegative.

Among Polish adult donors the serology was available for $79 \%$ (129/163). T. gondii seropositivity rate was $28 \%$ (36/129), while 72\% (93/129) donors were seronegative. The seroprevalence of Polish adult donors was higher than in Polish pediatric allo-HCT recipients $(28 \%$ vs $17 \%$, OR 1.94; 95\% CI 1.16-3.24; $\mathrm{p}=0.01)$. There was also significantly higher $T$. gondii seroprevalence among Polish adult donors than Polish pediatric donors (28\% vs $8 \%$, OR 4.38; 95\% CI 1.27-15.18; $\mathrm{p}=0.02$ ). No difference in seropositivity between Polish pediatric donors and allo-HCT recipients group was observed. There were no differences in seropositivity between adult donors with respect to country of origin (Table 2 ).

In 74\% (212/287) of donor-recipient pairs anti- $T$. gondii-IgG status was available, so we could assess donor-recipient serology combinations. In 63\% (133/212) of cases both donor and recipient were seronegative (D-/R-), 19\% (40/212) were D-/R+, 15\% (32/212) were D+/R- and 3.3\% (7/212) were $\mathrm{D}+/ \mathrm{R}+$.

Current practice in management of toxoplasmosis. In all Polish pediatric HCT centres post-transplant prophylaxis against $P j P$ was performed. In $87 \%$ (327/377) recipients, including $87 \%$ (250/287) allo-HCT and $86 \%(77 / 90)$ auto-HCT, TMP $6 \mathrm{mg} / \mathrm{kg} /$ day + SMX $30 \mathrm{mg} / \mathrm{kg} /$ day three times a week was used as anti-PjP prophylaxis active against $T$. gondii. Because of TMP/SMX adverse events or contraindications, in nine patients (allo-HCT only) aerolised pentamidine was used for PjP prophylaxis with no additional prophylaxis against $T$. gondii. Prospective PCR screening for infection/reactivation of $T$. gondii was done only one $(0.3 \%)$ patient.

Toxoplasmosis. During the period of present study, three cases of clinically overt toxoplasmosis were reported; all of them in allo-HCT recipients $(3 / 287$, i.e. $1.04 \%$ of
allo-HCT; or $3 / 377$, i.e. $0.8 \%$ of all HCTs). One of the cases was previously reported (patient 3 ) (see Zaucha-Prazmo et al. 2017). Toxoplasmosis was diagnosed at the probable level in two patients and possible level in one patient. Respective clinical data are presented in Table 3.

\section{DISCUSSION}

The geographical seroprevalence of toxoplasmosis in humans varies from less than ten to over 90 percent, depending on the country, due to regional differences of climate and life habits (Dard et al. 2018). For the Polish population the presence of anti-Toxoplasma gondii antibodies varies between $36 \%$ and $63 \%$, depending on region and population studied (Nowakowska et al. 2006, Salamon and Bulanda 2014, Milewska-Bobula et al. 2015, Samojlowicz et al. 2017).

There are no studies on toxoplasmosis seroprevalence in Polish HCT donors and recipients. In our study we found lower percentages of $T$. gondii seroprevalence in pediatric allo- and auto-HCT recipients (17\% and 14\%, respectively) in comparison to national data. Relatively low seroprevalence of Polish donors (23\%) could be explained by the high number of young donors $(23 \%$ were under 18 years, and only $8 \%$ of them had positive anti- $T$. gondii serostatus). This can be explained by increase in seroprevalence with age, which was observed both in Poland and other countries (Nowakowska et al. 2006, Olariu et al. 2015). In our study we observed $22 \%$ of Polish donors, $13 \%$ of allo-HCT and $53 \%$ of auto-HCT recipients were untested for T. gondii seroprevalence. These data correspond to those presented by Gajurel et al. (2015) where 19\% of pre-transplant allo-HCT recipients and $41 \%$ of auto-HCT recipients were not tested for infection of $T$. gondii. Therefore, performing pre-transplant serology is strongly recommended, irrespective of the expected rate of seropositivity (Ullmann et al. 2016, Decembrino et al. 2017).

We observed that prophylaxis with TMP/SMX against PjP which was active against $T$. gondii was conducted in all transplant centres ( $87 \%$ allo- and $86 \%$ of auto-HCT recipients). In 9 patients (all allo-HCT) pentamidine inhalation was used as a prophylaxis against $P j P$ with no additional prophylaxis against $T$. gondii. TMP/SMX seems to be the most common agent in toxoplasmosis prophylaxis (Gajurel et al. 2015, Ullmann et al. 2016) and its protective effect in prophylaxis is suggested (Martino et al. 2005, Gajurel et al. 2015). 
Table 3. Characteristics of three patients with toxoplasmosis.

\begin{tabular}{|c|c|c|c|}
\hline Patient/ Variable & 1 & 2 & 3 \\
\hline Gender/age (years) & $\mathrm{F} / 17$ & $\mathrm{M} / 9$ & $\mathrm{M} / 17$ \\
\hline Diagnosis & acute lymphoblastic leukemia & acute myeloblastic leukemia & Fanconi anemia \\
\hline Type of donor & MUD-PBSCT (10/10) & MUD-BMT (10/10) & MUD-BMT (10/10) \\
\hline Conditioning regimen & RIC (FLUD+TREO) & $\mathrm{MAC}(\mathrm{BU}+\mathrm{CY}+\mathrm{MEL})$ & RIC (FLUD+CY) \\
\hline GVHD prophylaxis & $\begin{array}{l}\text { ATG, CSA, MTX switched to TAC } \\
\text { after second PBSCT }\end{array}$ & ATG, CSA, MTX & ATG, CSA, MTX \\
\hline Engraftment day & +15 & +19 & +12 \\
\hline GVHD before toxoplasmosis & No & Yes, cGVHD, II ${ }^{\circ} \mathrm{GI}$ & No \\
\hline Anti-T.gondii IgG donor/recipient & $\mathrm{D} ? / \mathrm{R}+$ & $\mathrm{D}+/ \mathrm{R}+$ & $\mathrm{D}-/ \mathrm{R} ?$ \\
\hline $\begin{array}{l}\text { Post-transplant anti- } P j P \text { prophylaxis } \\
\text { active against } T \text {. gondii }\end{array}$ & $\begin{array}{c}\mathrm{TMP} 6 \mathrm{mg} / \mathrm{kg} / \mathrm{day}+\mathrm{SMX} 30 \mathrm{mg} / \mathrm{kg} / \\
\text { day three times a week }\end{array}$ & $\begin{array}{c}\mathrm{TMP} 6 \mathrm{mg} / \mathrm{kg} / \mathrm{day}+\mathrm{SMX} \\
30 \mathrm{mg} / \mathrm{kg} / \text { day three times a week }\end{array}$ & 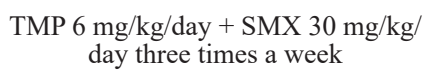 \\
\hline Post-transplant complications & graft loss, +57 second PBSCT & $\begin{array}{l}\text { EBV-DNA-emia treated with } \\
\text { rituximab, hypogammaglobulinemia }\end{array}$ & None \\
\hline $\begin{array}{l}\text { Toxoplasmosis symptoms onset (day } \\
\text { post HCT) }\end{array}$ & $\begin{array}{l}+58 \text { after first PBSCT/ }+1 \text { after } \\
\text { second PBSCT }\end{array}$ & +352 & +90 \\
\hline Symptoms of toxoplasmosis & fever, headache, vomiting & $\begin{array}{l}\text { visual impairment, } \\
\text { retinochorioiditis }\end{array}$ & $\begin{array}{l}\text { visual impairment, chorioiditis, } \\
\text { fever, concussions disorders, sensory } \\
\text { aphasia, headache }\end{array}$ \\
\hline Changes in CNS MRI & yes & yes & yes \\
\hline CSF general examination & $\begin{array}{l}\text { pleocytosis } 11 / \mu \mathrm{L}(100 \% \\
\text { lymphocytes), protein-raised, } \\
\text { glucose-normal }\end{array}$ & $\begin{array}{c}\text { pleocytosis } 10 / \mu \mathrm{L}(98 \% \\
\text { lymphocytes), protein-normal, } \\
\text { glucose-normal }\end{array}$ & $\begin{array}{c}\text { pleocytosis } 10 / \mu \mathrm{L}(95 \% \\
\text { lymphocytes), protein-raised, } \\
\text { glucose-normal }\end{array}$ \\
\hline Microbiological results & $\begin{array}{l}\text { PCR DNA positive for } T \text {. gondii in } \\
\text { blood and CSF }\end{array}$ & $\begin{array}{l}\text { PCR DNA positive for } T \text {. gondii in } \\
\text { vitreous, negative in blood and CSF }\end{array}$ & $\begin{array}{l}\text { PCR DNA negative for } T \text {. gondii } \\
\text { in blood and CSF, high levels and } \\
\text { avidity of anti- } T \text {. gondii- IgM and } \\
\text { IgG in blood and CSF }\end{array}$ \\
\hline Treatment of toxoplasmosis & TMP/SMX+CLIN+DX & $\begin{array}{l}\text { SULFADI+PYR+CLIN+DX } \\
\text { followed by } \\
\text { SULFADO+PYR+MP+DX }\end{array}$ & TMP+CLIN followed by TMP+DX \\
\hline Outcome of toxoplasmosis & Cured & Cured & Cured \\
\hline Toxoplasmosis level of diagnosis & Probable (CNS) & Probable (CNS+eye) & Possible (CNS+eye) \\
\hline
\end{tabular}

There are also some data about atovaquone, dapsone, pyrimethamine/sulfadoxine, azithromycin and clindamycin use as prophylactic agents in HCT recipients, but there are no randomised controlled trials evaluating the efficacy of $T$. gondii prophylaxis (Gajurel et al. 2015). According to guidelines (Ullmann et al. 2016) TMP/SMX prophylaxis, administered to most transplant patients to prevent $P j P$, is also efficacious in preventing toxoplasmosis, but no primary prophylaxis against $T$. gondii is recommended. Secondary prophylaxis should be administered for at least three months after a successful therapy of toxoplasmosis to prevent relapse of CNS toxoplasmosis (Ullmann et al. 2016). Pyrimethamine+sulfadiazine, pyrimethamine + clindamycin or atovaquone are proposed for secondary prophylaxis (Ullmann et al. 2016).

As in other studies (e.g., Hakko et al. 2013, Gajurel et al. 2015, Helton et al. 2016, Decembrino et al. 2017, Prestes et al. 2018), we also observed toxoplasmosis during TMP/ SMX prophylaxis in two of three patients. Suboptimal dosing, inadequate oral absorption and poor compliance may be reasons for this phenomenon (Gajurel et al. 2015).

Regular toxoplasmosis DNA PCR screening in HCT recipients is not recommended except for patients with clinical symptoms (Ullmann et al. 2016). In Polish pediatric HCT centres PCR screening for toxoplasmosis is not rou- tinely provided. In contrast, PCR follow-up of allo-HCT patients was implemented in France in half of centres (Robert-Gangneux et al. 2015). Some authors suggest to perfom real-time PCR screening of peripheral blood for all positive recipients with a seronegative donor, starting on the day of hematopoietic cell infusion, every 15 days during the engraftment period and subsequently every three months until CD4+ cell recovery occurs (Decembrino et al. 2017). Regular PCR follow-up of allo-HCT patients could guide pre-emptive treatment and improve outcome (Robert-Gangneux et al. 2015).

We observed that the TMP/SMX prophylaxis was routinely used in most patients after HCT, with a low percentage of clinically apparent toxoplasmosis in the Polish children after allo-HCT and no cases of toxoplasmosis in patients after auto-HCT. These facts question the use of routine prospective PCR monitoring of all patients after HCT. For this reason and due to high costs, a prospective screening is probably not necessary at all in auto-HCT children, and at least should be a matter of analysis in children after allo-HCT.

There is a logical relationship between global seroprevalence in the general population and the risk of reactivation in allo-HCT: the higher the pre-graft seroprevalence in the allo-HCT recipient population, the higher the incidence of 
toxoplasmosis reactivation (Dard et al. 2018). In our study we observed just three cases of clinically apparent toxoplasmosis, all in allo-HCT recipients (one percent) with no toxoplasmosis in auto-HCT recipients. Previous data on the incidence of toxoplasmosis in seropositive allo-HCT recipients vary from $0 \%$ in China to $20 \%$ in Japan, whereas it is $6-16 \%$ in European countries (France, Germany, Spain) (Gajurel et al. 2015). These data come mainly from adult transplant centres and suggest that incidence is lower in pediatric allo-recipients toxoplasmosis than in adult populations, which corresponds with lower T. gondii seroprevalence in younger age.

In just one patient with toxoplasmosis both donor and recipient $T$. gondii serostatus were known, whereas in full information was not available two cases. One of three patients received myeloablative conditioning regimen (MAC) and in all cases antithymocyte globulin (ATG) was used. In one case mild chronic graft-versus-host disease (GVHD) was seen before toxoplasmosis diagnosis. Meers et al. (2010) found that out of 208 monitored patients, 18 developed clinical toxoplasmosis (Meers et al. 2010). Out of 18,17 were seropositive and 14 received HCT from seronegative donors, suggesting that $T$. gondii negative serological status of donor is a risk factor of reactivation in seropositive patients (Meers et al. 2010). In addition, the main risk factors for toxoplasmosis reactivation are cord blood, haploidentical and mismatched unrelated donor HCT, low CD4+ cell count, MAC, total body irradiation, ATG use and severe GVHD (Gajurel et al. 2015, Decembrino et al. 2017, Dard et al. 2018). GVHD was seen in $59 \%$ of seropositive allo-HCT recipients, but has not been consistently associated with $T$. gondii reactivation (Gajurel et al. 2015).

We observed cerebral toxoplasmosis in three patients (two possible and one probable) with coexistence of ocular toxoplasmosis in two of them. The first symptoms were observed at day $+58,+90$ and +352 after HCT. All the patients responded to differential treatment with no fatal outcome. Gajurel et al. (2015) reported distribution of toxoplasmosis organ involvement $46 \%$ for CNS, $41 \%$ for disseminated disease, $8 \%$ for pulmonary involvement and $2 \%$ for simultaneous CNS and ocular involvement, while toxoplasmosis-related deaths were observed in $51 \%$ of patients.

Clinical manifestation of toxoplasmosis in allo-HCT recipients mainly occurs within the first six months after transplantation (Hakko et al. 2013, Dard et al. 2018, Prestes et al. 2018). There is no optimal treatment of toxoplasmosis in HCT patients contrary to HIV-patients (Dard et al. 2018). Pyrimethamine, sulfadiazine, TMP/SMX, clindamycin, atovaquone, doxycycline, dapsone, azitromycin in various doses, combinations and different times were used in T. gondii infection treatment (Hakko et al. 2013, Gatti-Mays et al. 2016, Dard et al. 2018).

In conclusion, we observed higher anti-T. gondii-IgG seroprevalence in Polish adult donors in comparison to pediatric allo-HCT recipients and pediatric allo-HCT donors, thus its prevalence increases with age. We also observed that most of HCT patients received prophylaxis against $P j P$ with TMP/SMX, which is active against $T$. gondii. However, its use depends on transplant centre practice. No prospective PCR screening for $T$. gondii infection is provided in Polish pediatric transplant centres. Finally, we have shown that toxoplasmosis in our country was rare and occurred only in the group of allo-HCT recipients. Current diagnostics and different treatment in each patient with antiprotozoal treatment was effective and resulted in full recovery. Since pre-HCT T. gondii serology was not assessed in all HCT recipients, we suggest this test should be standard practice but standardisation of management of infection of $T$. gondii in children after HCT is needed.

Acknowledgements. The authors thank the Editor-in-Chief and anonymous reviewer for their suggestions to improve the article.

\section{REFERENCES}

Berrett A.N., Gale S.D., Erickson L.D., Thacker E.L., Brown B.L., Hedges D.W. 2018: Toxoplasma gondii seropositivity and substance use in US adults. Folia Parasitol. 65: 011.

Dard C., Marty P., Brenier-Pinchart M.P., Garnaud C., Fricker-Hidalgo H., Pelloux H., Pomares C. 2018: Management of toxoplasmosis in transplant recipients: an update. Expert Rev. Anti. Infect. Ther. 16: 447-460.

Decembrino N., Comelli A., Genco F., Vitullo A., Recupero S., Zecca M., Meroni V. 2017: Toxoplasmosis disease in paediatric hematopoietic stem cell transplantation: do not forget it still exists. Bone Marrow Transplant. 52: 1326-1329.

Gajurel K., Dhakal R., Montoya J.G. 2015: Toxoplasma prophylaxis in haematopoietic cell transplant recipients: a review of the literature and recommendations. Curr. Opin. Infect. Dis. 28: 283-292.

Gatti-Mays M.E., Manion M., Bowen L.N., Brown G.T., Danner R.L., Khan O., Nath A., Battiwalla M., BarRetT A.J., Ito S. 2016: Toxoplasmosis encephalitis with immune-reconstitution inflammatory syndrome in an allogeneic stem cell transplant patient: a case report. Bone Marrow Transplant. 51: 1622-1624.

Hakko E., Ozkan H.A., Karaman K., Gulbas Z. 2013: Analysis of cerebral toxoplasmosis in a series of 170 allogeneic hematopoietic stem cell transplant patients. Transpl. Infect. Dis. 15: 575-580.

Helton K.J., Maron G., Mamcarz E., Leventaki V., Patay Z., SAdighi Z. 2016: Unusual magnetic resonance imaging presentation of post-BMT cerebral toxoplasmosis masquerading as meningoencephalitis and ventriculitis. Bone Marrow Transplant. 51: 1533-1536.

Isa F., Saito K., Huang Y.T., Schuetz A., Babady N.E., Salvatore S., Pessin M., van Besien K., Perales M.A., Giralt S., Sepkowitz K., Papanicolaou G.A., Soave R., Kamboj M. 2016: Implementation of molecular surveillance after a cluster of fatal toxoplasmosis at 2 neighboring transplant centers. Clin. Infect. Dis. 63: 565-568.

Luungman P., de la Camara R., Cordonnier C., Einsele H., Engelhard D., Reusser P., Styczynski J., Ward K. 2008: Management of CMV, HHV-6, HHV-7 and Kaposi-sarcoma 
herpesvirus (HHV-8) infections in patients with hematological malignancies and after SCT. Bone Marrow Transplant. 42: 227-240.

Martino R., Bretagne S., Einsele H., Maertens J., Ullmann A.J., Parody R., Schumacher U., Pautas C., Theunissen K., Schindel C., Muñoz C., Margall N., CorDONNIER C. 2005: Early detection of Toxoplasma infection by molecular monitoring of Toxoplasma gondii in peripheral blood samples after allogeneic stem cell transplantation. Clin. Infect. Dis. 40: 67-78.

Martino R., Maertens J., Bretagne S., Rovira M., Deconinck E., Ullmann A.J., Held T., Cordonnier C. 2000: Toxoplasmosis after hematopoietic stem cell transplantation. Clin. Infect. Dis. 31: 1188-1195.

Meers S., Lagrou K., Theunissen K., Dierickx D., Delforge M., Devos T., Janssens A., Meersseman W., Verhoef G., Van Eldere J., Maertens J. 2010: Myeloablative conditioning predisposes patients for Toxoplasma gondii reactivation after allogeneic stem cell transplantation. Clin. Infect. Dis. 50: $1127-1134$.

Milewska-Bobula B., Lipka B., Golab E., Debski R., Marczynska M., Paul M., Panasiuk A., Seroczynska M., Mazela J., Dunin-Wasowicz D. 2015: Recommended management of Toxoplasma gondii infection in pregnant women and their children. Przegl. Epidemiol. 69: 291-298.

Nowakowska D., Stray-Pedersen B., Spiewak E., Sobala W., Malafiej E., Wilczynski J. 2006: Prevalence and estimated incidence of Toxoplasma infection among pregnant women in Poland: a decreasing trend in the younger population. Clin. Microbiol. Infect. 12: 913-917.

Olariu T.R., Petrescu C., Darabus G., Lighezan R., Mazilu O. 2015: Seroprevalence of Toxoplasma gondii in Western Romania. Infect. Dis. 47: 580-583.

Prestes D.P., Mendes C., Batista M.V., Ramos J.F., Junior J.S., OKay T.S., Caiaffa H., Rocha V.G., Costa S.F. 2018: A case-series of toxoplasmosis in hematopoietic stem cell trans- plantation: still a concern for endemic countries. Bone Marrow Transplant. 53: 1333-1339.

Robert-Gangneux F., Sterkers Y., Yera H., Accoceberry I., Menotti J., Cassaing S., Brenier-Pinchart M.P., Hennequin C., Delhaes L., Bonhomme J., Villena I., Scherer E., Dalle F., Touafek F., Filisetti D., Varlet-Marie E., Pelloux H., Bastien P. 2015: Molecular diagnosis of toxoplasmosis in immunocompromised patients: a 3-year multicenter retrospective study. J. Clin. Microbiol. 53: 1677-1684.

Salamon D., Bulanda M. 2014: Toxoplasma gondii and women of reproductive age: an analysis of data from the Chair of $\mathrm{Mi}$ crobiology, Jagiellonian University Medical College in Cracow. Ann. Parasitol. 60: 291-296.

Samojlowicz D., Borowska-Solonynko A., Kruczyk M. 2017: New, previously unreported correlations between latent Toxoplasma gondii infection and excessive ethanol consumption. Forensic Sci. Int. 280: 49-54.

StyCZYNSKi J., Gil L. 2008: Prevention of infectious complications in pediatric HSCT. Bone Marrow Transplant. 42 Suppl. 2: S77-81.

Styczynski J., Reusser P., Einsele H., de la Camara R., Cordonnier C., Ward K.N., Ljungman P., Engelhard D. 2009: Management of HSV, VZV and EBV infections in patients with hematological malignancies and after SCT: guidelines from the Second European Conference on Infections in Leukemia. Bone Marrow Transplant. 43: 757-770.

Ullmann A.J., Schmidt-Hieber M., Bertz H., Heinz W.J., Kiehl M., Kruger W., Mousset S., Neuburger S., Neumann S., Penack O., Silling G., Vehreschild J.J., EinseLe H., Maschmeyer G. 2016: Infectious diseases in allogeneic haematopoietic stem cell transplantation: prevention and prophylaxis strategy guidelines 2016. Ann. Hematol. 95: 1435-1455.

Zaucha-Prazmo A., Samardakiewicz M., Dubelt J., KowALCZYK J.R. 2017: Cerebral toxoplasmosis after haematopoietic stem cell transplantation. Ann. Agric. Environ. Med. 24: $237-239$.

Cite this article as: Czyzewski K., Fraczkiewicz J., Salamonowicz M., Pieczonka A., Zajac-Spychala O., Zaucha-Prazmo A., Gozdzik J. and Styczynski J. 2019: Low seroprevalence and low incidence of infection with Toxoplasma gondii in pediatric hematopoietic cell transplantation donors and recipients: Polish nationwide study. Folia Parasitol. 66: 019. 